\title{
A FORMAÇÃO DE PROFESSORES DE LÍNGUA PORTUGUESA COMO L2 PARA SURDOS: SABERES-FAZERES DA PRÁTICA DOCENTE
}

\author{
TEACHERS' TRAINING OF PORTUGUESE LANGUAGE AS L2 TO DEAF PEOPLE: TEACHING \\ PRACTICE CONCEPTS
}

\section{Luciane Ferreira Bomfim ${ }^{1}$, Cláudia Paranhos de Jesus Portela ${ }^{2}$, Dídima Maria de Mello Andrade $^{2}$}

${ }^{1}$ Prefeitura de São Francisco do Conde, São Francisco do Conde, BA, Brasil

lucianebomfim.Ib@gmail.com

2 Universidade do Estado da Bahia (UNEB), Salvador, BA, Brasil

claudiaparanhos3@gmail.com, didima.andrade@gmail.com

Recebido em 5 out. 2018

Aceito em 13 nov. 2018

Resumo: Esse estudo tem por objetivo apresentar de que maneira a formação continuada para professores pode colaborar para a ressignificação das práticas pedagógicas dos docentes de Língua Portuguesa para surdos como L2. Por considerar que ministrar aulas na modalidade de uma segunda língua exige do professor metodologias didáticas adequadas, levando-se em conta que é uma segunda língua viso-espacial, portanto, diferente de como se ensina para pessoas ouvintes, foi desenvolvido um projeto de intervenção com proposta direcionada para a formação continuada, organizando oficinas formativas para professores que trabalham com educandos surdos, no que concerne ao ensino da Língua Portuguesa como L2 no município de São Francisco do Conde/Bahia, Brasil. Como metodologia, foi utilizada a pesquisa participante e, como instrumento de coleta de dados, o diário de bordo. O lócus da pesquisa foi o município de São Francisco do Conde (SFC) e os sujeitos foram os professores das escolas de surdos de Salvador/Bahia, Brasil, como também os professores das escolas inclusivas de SFC, que trabalham na sala de recursos, no Atendimento Educacional Especializado. A relevância deste estudo se justifica na medida em que acrescentamos outras discussões aos escassos trabalhos já publicados sobre a temática da formação inicial de professores para o ensino da Língua Portuguesa como L2, por conseguinte, buscando trazer novas perspectivas às lacunas deixadas.

Palavras-chave: Formação de professores. Educação de surdos. Língua portuguesa como L2.

\begin{abstract}
The purpose of this study is to show how continuing education courses for teachers can contribute to build new meanings onto the pedagogical practices for deaf people's Portuguese teachers as L2. Considering that Portuguese classes as a second language require appropriate teaching methodologies and taking into account that it is a second visuospatial language (therefore, it differs from how it is taught to hearing people), an interventional project was designed from a purpose aimed at a continuing education course, by organizing training workshops for teachers who deal with deaf students, teaching them Portuguese as L2 in the city of São Francisco do Conde/Bahia, Brazil. A participant research was used as a methodological path and the logbook was the instrument of data collection. The research was held in the city of São Francisco do Conde (SFC) and as its subjects figure both teachers from deaf schools in Salvador and SFC's inclusive schools, which work in Specialized Educational Services. The relevance of this study lies in the fact that we add other discussions to the scarce works published about initial formation for Portuguese teachers as L2 so far, hence it brings new perspectives to the blanks left behind.
\end{abstract}

Keywords: Teacher Training. Deaf People Education. Portuguese as L2. 


\section{INTRODUÇÃO}

Dentre os vários desafios na educação dos surdos, ensinar Língua Portuguesa escrita é mais um deles, isto porque muitos destes alunos não fizeram a aquisição da L1, ou seja, não tem ainda uma língua constituída, o que impossibilita a aprendizagem da L2, pois, neste processo de transição, a L1 irá mediar a aprendizagem da L2. Até recentemente (talvez até hoje), o ensino da Língua Portuguesa se dava na modalidade oral, em que se fazia uso da leitura labial, e isso dificultava sua aprendizagem, levando o aluno a adquirir apenas fragmentos da língua.

Com a aprovação do Decreto 5.626/05, esta situação começa a modificar e as escolas passam a ser obrigadas a possibilitar o ensino bilíngue. Isto exigiria profissionais especializados, porém o problema é que nem mesmo o referido Decreto que dispõe sobre esse ensino define de maneira clara a formação do professor de Língua Portuguesa e nem todas as IES (Instituição de Ensino Superior) oferecem essa disciplina nos cursos de Letras e Pedagogia.

Para que o aluno surdo aprenda a $L 2$, é preciso que ele domine a $L 1$, a fim de que possa compreender melhor a leitura e a escrita, entretanto nem sempre isto acontece. Sua inserção em classes inclusivas desde a educação infantil o impossibilita de ter contato com outros pares não ouvintes e com professores fluentes na Língua de Sinais, assim ele não consegue desenvolver a fluência na L1 e, por conseguinte, estar apto para a aquisição da sua primeira língua.

Este contexto resulta na dificuldade em aprender a segunda língua, o português. O ideal seria que estes alunos fossem inseridos em escolas especializadas na educação de surdos e, só depois do processo de aquisição da Língua de Sinais, eles fossem inseridos nas classes regulares por volta do $6^{\circ}$ ano, depois de ter realizado a aquisição da L1. Os estudos feitos por Capovilla (2009) comprovam que nem mesmo o Atendimento Educacional Especializado (AEE) - em se tratando de educação de surdos - substituiu as escolas bilíngues. Os surdos precisam de um espaço no qual os professores sejam fluentes na Língua de Sinais e a comunidade escolar seja sinalizadora e que as crianças tenham como referência os seus pares surdos. 
Como resultado deste cenário, temos um déficit na educação dos surdos, ocasionando problemas no ensino e na aprendizagem da Língua Portuguesa como L2. Ministrar aulas na modalidade de uma segunda língua exige do professor metodologias didáticas adequadas, levando-se em conta que é uma segunda língua que não é oral, portanto, diferente de como se ensina para ouvintes.

Com base neste panorama, desenvolvemos um projeto de intervenção em que propomos formação continuada, organizando oficinas formativas para professores que trabalham com educandos surdos, no que concerne ao ensino da Língua Portuguesa como L2 no município de São Francisco do Conde/Bahia/Brasil. Foram escolhidos para fazer as formações profissionais quem já trabalha com essa temática em escolas de surdos, ou seja, os professores que atuam com esta modalidade nas classes inclusivas no AEE no município, possibilitando, assim, a troca de experiências e práticas já instituídas em sala de aula. Logo, foi produzido, durante as oficinas, um material didático que servirá para oferecer subsídios didáticos para a prática do professor.

Este trabalho teve por objetivo apresentar de que maneira a formação continuada para professores pode colaborar para a ressignificação das práticas pedagógicas dos docentes de Língua Portuguesa para surdos como L2. A metodologia utilizada neste estudo foi a pesquisa participante, na qual utilizamos como instrumento para coleta de dados o diário de bordo. O lócus da pesquisa foi o município de São Francisco do Conde e os sujeitos foram os professores das escolas de surdos de Salvador/Bahia, como também os professores das escolas inclusivas de SFC, que trabalham na sala de recursos, no Atendimento Educacional Especializado.

A relevância desta pesquisa se justifica na medida em que acrescentamos outras discussões aos trabalhos já publicados sobre a temática da formação inicial de professores para o ensino da Língua Portuguesa como L2. Por conseguinte, buscando trazer novas perspectivas às lacunas existentes. Para a discussão, traremos autores que abordam os temas da surdez, da formação de professores e da Língua Portuguesa para surdos.

\section{EDUCAÇÃO BILÍNGUE PARA SURDOS}


Ao longo dos anos, foram desenvolvidas distintas metodologias e abordagens para ensinar os surdos, dentre elas, destacamos: o Bilinguismo, surgido no final da década de 80 , fruto do fracasso das abordagens anteriores e das reivindicações dessa minoria pelos direitos linguísticos e culturais. A proposta bilíngue na educação de surdos ganha força na década de 90 e passa a ser a abordagem mais desejada por surdos no mundo inteiro. Para Goldfeld (1997, p. 38):

\begin{abstract}
O Bilinguismo tem como pressuposto básico que o surdo deve ser Bilíngue, ou seja, deve adquirir, como língua materna, a língua de sinais, que é considerada à língua natural dos surdos e, como segunda língua, a língua oficial de seu país [...]. Os autores ligados ao Bilinguismo percebem o surdo de forma bastante diferente dos autores Oralistas e da Comunicação Total. Para os bilinguistas, o surdo não precisa almejar uma vida semelhante ao ouvinte, podendo assumir sua surdez. (GOLDFELD, 1997, p. 38)
\end{abstract}

Esta abordagem visa a atender não apenas às necessidades linguísticas e aos aspectos relacionados à mudança na escolarização dos surdos, mas também oporse às práticas pedagógicas apresentadas nas abordagens anteriores, em que não se levavam em conta as particularidades identitárias e culturais desses sujeitos, já que visam à aceitação da surdez como uma diferença, e não como uma deficiência sem almejar a ouvintização ${ }^{1}$ desses sujeitos.

Os teóricos defensores dessa abordagem partem de uma concepção socioantropológica, em que a surdez passa a ser vista como uma diferença, e não como deficiência. Para Skliar (2010), as mudanças decorrentes do aprofundamento teórico sobre a surdez, fundamentado numa visão socioantropológica, são importantes, mas ainda não podem ser consideradas por si só como suficientes para firmar um novo olhar sobre a surdez, pois existem muitas limitações na organização de projetos políticos e direitos linguísticos. Segundo este pressuposto, o que diferencia um surdo de um ouvinte não é apenas a audição, mas os contextos sociais, visuais e culturais em que os surdos podem estar inseridos.

Por ser recente esta abordagem educacional, o Bilinguismo, que defende a ideia de que a língua de sinais é a língua dos surdos, sua língua materna e, como segunda língua, a língua escrita do seu país - aqui no Brasil, a Língua Portuguesa -, está proposto a enfrentar uma série de obstáculos para poder se consolidar. Isso vai

\footnotetext{
${ }^{1}$ Os termos ouvintista, ouvintismo e ouvintização são derivações que, segundo a concepção de Skliar (2010, p. 7) sugere "uma forma particular e específica de colonização dos ouvintes sobre os surdos".
} 
desde as múltiplas concepções sobre o Bilinguismo até a carência de profissionais habilitados. Países como Finlândia e Suécia já desenvolvem essa abordagem de forma mais sistemática.

O Decreto 5.626/05 valida a educação bilíngue conforme exposto:

Art. 22. As instituições federais de ensino responsáveis pela educação básica devem garantir a inclusão de alunos surdos ou com deficiência auditiva, por meio da organização de:

I- escolas e classes de educação bilíngue, abertas a alunos surdos e ouvintes, com professores bilíngues, na educação infantil e nos anos iniciais do ensino fundamental;

II - escolas bilíngues ou escolas comuns da rede regular de ensino, abertas a alunos surdos e ouvintes, para os anos finais do ensino fundamental, ensino médio ou educação profissional, com docentes das diferentes áreas do conhecimento, cientes da singularidade linguística dos alunos surdos, bem como com a presença de tradutores e intérpretes de Libras - Língua Portuguesa. (BRASIL, 2005, grifo nosso).

Como observado, o Decreto prevê para a educação dos surdos bem mais que uma abordagem bilíngue para ser adotada em ambientes ouvintes. Ele prediz uma proposta de educação especializada denominada de escola e/ou classes bilíngues. Escola para surdos, um espaço que visa às especificidades destes educandos e propicia o fortalecimento da sua cultura, além de fomentar uma identidade surda independentemente de suas diferenças e complexidades, oferecendo possibilidades de aproximação entre as culturas surdas e ouvintes. Uma escola onde não existem imposições de "normalidades" e nem o ouvintismo.

Apesar das conquistas das últimas décadas pelo reconhecimento de Libras como língua e da educação bilíngue, com a atual política de inclusão, contemplamos alguns retrocessos desses direitos já adquiridos, como o fechamento de algumas das escolas especializadas que, durante anos, desenvolveram um trabalho mais sistematizado na educação desses alunos, tanto na aquisição da L1 como no ensino da L2.

Como esta proposta é nova, para que a educação bilíngue consiga se estruturar, alguns desafios precisam ser solucionados. Para isso, são necessários espaços educacionais adequados, com um quadro de profissionais qualificados, composto por pessoas surdas, como também reestruturação pedagógica (recursos imagéticos e língua de sinais) com metodologias que não se fundamentam em técnicas de memorização em decorrência de um aprendizado mecânico e descontextualizado, além de materiais didáticos adaptados e compatíveis com a educação dos surdos. 


\section{FORMAÇÃO DE PROFESSORES PARA O ENSINO DA LÍNGUA PORTUGUESA COM L2}

Nos últimos anos, têm surgido inquietações quanto à formação do professor de surdos, frente à particularidade dessa competência. No presente, o desafio é compreender o papel do professor de surdos no contexto das novas políticas educacionais e, entender que o processo de formação inicial e continuada para professores de surdos precisa de procedimento diferenciado. Não quero dizer, contudo, que, para as outras especificidades, não seja necessário, isto porque, partindo do pressuposto de que a língua de sinais é a primeira língua dos surdos, é fundamental que o profissional que irá trabalhar com esses alunos tenha 0 conhecimento gramatical e o domínio da língua de sinais para que possa desenvolver um trabalho sistemático.

A educação dos alunos surdos é um tema ainda incompreendido pela maioria dos profissionais. Durante décadas, e até hoje, estes sujeitos são vistos como deficientes, com base num modelo clínico terapêutico, em que o surdo precisa falar para aprender e ser como o ouvinte. Desconstruir esse modelo é, atualmente, um dos desafios da educação dos surdos, pois a forma como tais sujeitos são vistos implicará a maneira como estes profissionais irão desenvolver suas práticas.

$\mathrm{Na}$ busca de obter um panorama sobre as publicações existentes sobre a educação dos surdos e analisar o que vem sendo produzido nesta área, nos debruçamos sobre o estado da arte das publicações de dissertações e teses existentes e disponíveis no Brasil, no intuito de levantar as lacunas que há na literatura da área e estabelecer os vínculos da educação dos não ouvintes com a formação dos professores de Língua Portuguesa como L2 no Brasil.

Segundo Charlot (2006, p. 17), as pesquisas educacionais aqui no Brasil não costumam revistar o que já tem sido produzido anteriormente, faltando "memória", o que resulta em reproduções de trabalhos acadêmicos com os mesmos temas, já amplamente discutidos, dificultando o progresso da pesquisa no campo. "Para que progrida a pesquisa em educação no Brasil, para que ela se organize, ganhe visibilidade, para que se definam, pouco a pouco, 'pontos de partida' e ponto de apoio, existe um trabalho a ser feito". 
Então, procuramos alguns trabalhos já existentes na área e que pudessem nortear o trabalho. Encontramos 02 (dois) materiais que apresentavam o estado da arte sobre a educação dos surdos no Brasil: Ramos (2013) e Pagnez e Sofiato (2014). Ambos realizaram um estudo bibliográfico, analisando os resumos das dissertações e teses do Banco de Teses da Capes, em períodos distintos. A primeira autora analisou o período de 2005 a 2009, enquanto as outras analisaram o período de 2007 a 2011.

Com base nesses trabalhos, direcionamos a pesquisa para procurar na Biblioteca Digital Brasileira de Teses e Dissertações (BDTD), coordenada pelo Instituto Brasileiro de Informação em Ciência e Tecnologia (IBICT) e vinculada ao Ministério da Ciência, Tecnologia e Inovação (MCTI). Para acesso a esse banco de dados, utilizamos os termos de busca "educação de surdos", "formação de professores" e "Língua Portuguesa como L2", empregando o recurso "Procura Avançada" e realizando a procura segundo os campos "Resumo em português" e "Ano de Defesa". No período definido para a pesquisa - 2012 a 2016 -, foram obtidas 30 (trinta) produções nos cursos de mestrado e doutorado.

Dentre as 30 (trinta) dissertações apresentadas pelo sistema, apenas a metade foi analisada. As demais não estavam disponíveis, eram repetidas ou não estavam adequadas ao escopo da pesquisa. Entre as 15 (quinze) dissertações e teses selecionadas, 06 (seis) trabalhos se aproximam mais da temática.

Outra análise desenvolvida foi à comparação da matriz curricular de alguns cursos de instituições públicas no Estado da Bahia que oferecem o curso de Pedagogia e Letras /Libras. No curso de Pedagogia da UNEB (Universidade do Estado da Bahia) e da UFBA (Universidade Federal da Bahia), percebemos que estas instituições não contemplam, em sua matriz curricular, a disciplina de Língua Portuguesa para surdos. Nas licenciaturas em Letras/Libras, equiparando com a da UFSC (Universidade Federal de Santa Catarina), polo UFBA e o da UFRB (Universidade Federal do Recôncavo da Bahia), mesmo sendo cursos voltados ao ensino ou dando ênfase a Libras, o componente de ensino da Língua Portuguesa para surdos não é contemplado ou aparece como matéria optativa.

Como a educação dos surdos ainda estar a debutar aqui no Brasil, tratando da formação do docente de Língua Portuguesa para surdos, temos poucas pesquisas, existindo a necessidades de novos estudos nesta área e de medidas interventivas 
que venham a modificar o atual cenário da educação dos não ouvintes. Os cursos de licenciatura em Letras/Libras formam apenas para professores de Libras, já que nas matrizes curriculares dos cursos não constam nenhuma matéria com o intuito de formar professores para o ensino da Língua Portuguesa escrita com L2.

Importante destacar que a formação de professores para educação especial está regulada pelas propostas expressas nos documentos: Proposta de Diretrizes para a Formação Inicial de Professores da Educação Básica em curso de nível superior (CNE/CP) 9 de 2001; Resolução do Conselho Nacional de Educação/Conselho Pleno (CNE/CP) $\mathrm{n}^{\circ} 2$ de 2015, que define as Diretrizes Curriculares Nacionais para a Formação inicial em nível superior (cursos de licenciatura, cursos de formação pedagógica para graduados e cursos de licenciatura) e para a formação continuada.

Sobre a questão, Bueno (1999) afirma que o professor "especialista" pode muito contribuir com o professor "generalista", todavia isto não vem ocorrendo. Segundo ele, se, por um lado,

[...] os professores do ensino regular não possuem preparo mínimo para trabalhar com crianças que apresentem diferentes deficiências evidentes e, por outro, grande parte dos professores do ensino especial tem pouco contribuído com o trabalho pedagógico desenvolvido no ensino regular. Isso se dá por esses professores terem calçado e construído sua competência nas dificuldades específicas do alunado por eles atendido, pois o que tem caracterizado a atuação de professores de surdos, cegos, deficientes mentais, com raras e honrosas exceções, é a centralização quase absoluta de suas atividades na minimização dos efeitos específicos das mais variadas deficiências (BUENO, 1999, p. 13).

Embora as atividades desenvolvidas no AEE no contra turno, se distingam daquelas realizadas nas classes comuns, este atendimento serve para complementar a formação do aluno surdo, devendo o mesmo ser articulado com a proposta do ensino comum, conforme prevê o PNEE-El/08. Os profissionais que irão atuar na educação especial deverão ter como base de sua formação, inicial e continuada, conhecimentos gerais da docência e conhecimentos específicos da área, no caso dos que irão trabalhar com alunos surdos e conhecimentos no ensino da Língua Brasileira de Sinais (Libras) e Língua Portuguesa na modalidade escrita como segunda língua.

Como podemos perceber, a educação dos surdos se difere das demais, sendo bem específica, atuando com diferentes profissionais e em diferentes momentos, 
segundo o material criado pelo MEC/Secretaria de Educação Especial (SEESp) 2008 - "Formação continuada à distância de professores para o atendimento educacional especializado" -, cujo objetivo era oferecer fundamentos básicos para professores-alunos em AEE dos municípios polos e divulgar suas atividades. No material, a parte voltada para surdez indica o AEE em três momentos: Atendimento Educacional Especializado em Libras; Atendimento Educacional para o Ensino de Libras e Atendimento Educacional para o Ensino de Português.

Apesar de todos os documentos já apresentados sinalizarem a necessidade do ensino da Língua Portuguesa escrita como L2, seja ela por decreto, através da inclusão das disciplinas nos cursos de formação e no atendimento dos alunos ensinando esta modalidade, o que nos causa surpresa é saber que algumas IES não disponibilizam esta disciplina, que é tão importante quanto a Libras. Entendemos que apenas oportunizar este componente curricular não será suficiente para que o professor consiga vencer os desafios do seu trabalho com os alunos surdos, porém, esses conhecimentos, ainda que básicos, são essenciais para formação desses professores.

Se a educação do surdo é bilíngue não se pode negligenciar ao futuro professor conhecimentos basilares sobre a L2 deste aluno. Embora seja a língua nativa do nosso País, ela se apresenta na estrutura de uma segunda língua. Diante disso, cabe-nos perguntar como este profissional poderá implementar em seus planos de aula, estratégias e metodologias de segunda língua se, na sua formação inicial, nunca aprendeu? Independentemente de se tratar de escolas comuns (regulares) ou escolas especializadas, o que irá resolver os entraves da educação dos surdos será o tipo de ensino ofertado a esse aluno.

$\mathrm{Na}$ tentativa de solucionar o problema de ausência de formação e contribuir com esse processo formativo docente, propomos organizar oficinas formativas para os professores que trabalham com educandos surdos do Fundamental I e II no AEE, no município de São Francisco do Conde, Estado da Bahia, Brasil, no que concerne ao ensino da Língua Portuguesa como L2, ofertando a estes profissionais instrumentos, através dos quais possam refletir sobre suas ações para transformação do seu fazer pedagógico. Dessa forma, para realizar as oficinas formativas, convidamos profissionais que já trabalham com este componente 
curricular em escolas especializadas na educação de surdos em Salvador, a fim de compartilharem suas experiências.

\section{OFICINAS DE LÍNGUA PORTUGUESA COMO L2 PARA SURDOS}

Dada a ausência de uma construção específica para a formação dos professores que atuam com alunos surdos no ensino da Língua Portuguesa, estruturamos oficinas formativas como investimento na preparação destes profissionais. As oficinas de Língua Portuguesa para surdos começaram a ser ofertadas aos professores de Libras do município de SFC, em 2017.

Desse modo, foram responsáveis pelas oficinas 04 (quatro) professoras que trabalham em escolas especializadas de surdos, em Salvador há alguns anos com experiência no ensino e na alfabetização em Libras e em Português como L2 para crianças surdas. Como cursistas, frequentaram o curso 07 (sete) professoras de Libras do município de SFC que atuam no Ensino Fundamental I e II e uma coordenadora pedagógica, que acompanha as professoras de Libras. É importante destacar que 02 (duas) coordenadoras do Núcleo de Libras, ligadas à Secretaria de Educação do município, também acompanharam as oficinas para observar e participar do desenvolvimento da formação, ambas com conhecimento em Libras.

As formações aconteceram durante o turno de trabalho das professoras e das coordenadoras. A SEDUC encaminhava um Comunicado Interno $(\mathrm{Cl})$ para os gestores solicitando a liberação dos profissionais nos dias previamente agendados. Foram 04 (quatro) encontros, um a cada mês, cujo objetivo era subsidiar a prática docente no que diz respeito à importância da Libras e das metodologias de ensino de Língua Portuguesa como segunda língua. Os métodos utilizados pelos professores que ministraram as oficinas consistiam, no primeiro momento, de exposição e discussão do texto anteriormente enviado e, no segundo momento, a parte mais prática das atividades propostas.

A escolha por estes profissionais para fazer as formações se deu por sua experiência de vida e profissional. Conforme Tardif (2002, p. 17), "o saber do professor traz em si mesmo as marcas do seu trabalho, que ele não é somente como um meio no trabalho, mas é produzido e modelado no e pelo trabalho". O autor destaca a importância de se levar em consideração os saberes cotidianos do 
trabalho dos professores e chama a atenção para a escassez de pesquisas no meio escolar em contato direto com os professores na área da ciência da educação.

Com base nestas perspectivas, a pesquisa foi desenvolvida o mais próximo possível do "chão da escola", trocando experiências com colegas de trabalho que utilizam o saber experiencial ou prático (o saber fazer ou saber ser). Tardif (2002, p. 48-49) chama de saberes experienciais o:

[...] conjunto de saberes atualizados, adquiridos e necessários no âmbito da prática da profissão docente e que não provêm de instituições de formação nem dos currículos. Estes saberes não se encontram sistematizados em doutrinas ou teorias. São saberes práticos (e na prática: eles não se superpõem à prática para melhor conhecê-la, mas se integram a ela e dela são partes constituintes enquanto prática docente) e formam um conjunto de representações a partir das quais os professores interpretam, compreendem e orientam sua profissão e sua prática cotidiana em todas as suas dimensões. (TARDIFF, 2002, p. 48-49)

Ninguém sai de um curso de graduação, por melhor que este seja pronto para os desafios que irá encontrar na sala de aula, porque o conhecimento teórico que o professor adquiriu não irá prepará-lo, de todo, para os contextos tão diversos das escolas e, no dia a dia, nos erros e acertos. É a partir de suas práticas que ele irá complementando seu estudo, pois formação do professor é um processo, portanto, deve ser contínuo.

Por isso, esta formação foi proposta aproximando-se do "chão da escola" e dos seus atores, afinal, é neste espaço que acontecem o debate, a análise crítica, a troca de experiências, a reflexão sobre a prática e a construção de novos saberes. Nesse sentido, Freire (1996, p. 37) infere que "o pensar certo é tomado em si mesmo e dele se fala ou uma prática puramente se descreve, mas algo que se faz e que se vive enquanto dele se fala com força do testemunho."

Os temas das oficinas não surgiram de forma aleatória, mas partiram de discussões anteriores com os professores formadores sobre a realidade da educação dos surdos no município: alunos sem aquisição de $L 1$, os que já faziam uso da Língua de Sinais, porém sem terem passado pelo processo de alfabetização/letramento. Com base nas informações prestadas para atender às necessidades das oficinas, foi montado o plano de ação.

Após elaboração do plano de ação das oficinas apresentamos aos cursistas os temas, que foram debatidos se atenderiam às demandas dos professores. Depois, 
foi a vez de aguardar sugestões para indicação de outros temas se assim desejassem. Por se tratar de uma pesquisa de cunho participativo, buscamos em todas as etapas desse processo a participaçãolcolaboraçãolintervenção ativa e efetiva dos sujeitos envolvidos na formação docente, pautados em Freire (1996, p. 38) que enfatiza "A prática docente crítica, implicante do pensar certo, envolve o movimento dinâmico, dialético, entre o fazer e o pensar sobre o fazer."

Os textos e a pauta foram entregues aos cursistas previamente para que pudessem se preparar para o dia da formação. No primeiro momento de cada oficina, procediam-se às discussões teóricas e, nesta ocasião, aproveitava-se também para tirar dúvidas, socializar o trabalho que estava sendo desenvolvida, era à hora da troca de experiências.

No segundo período da oficina, ocorria à parte prática, momento em que eram feitas as atividades. Ao término de cada oficina, os professores cursistas tinham a incumbência de concluir a atividade iniciada na formação. Estas eram voltadas para a realidade escolar de cada docente, ou seja, eles já elaboravam as atividades pensando nas necessidades dos seus educandos, alimentando o ciclo dialético de pensar, fazer, testar, repensar e refazer.

Esta possibilidade é necessariamente marcada pela construção de conhecimentos por parte dos professores, a partir da análise crítica das práticas e da ressignificação das teorias, a partir dos conhecimentos da prática. Sendo assim, podemos afirmar que a tomada de decisão do professor no cotidiano escolar perpassa pela relação teoria e prática, gerando dessa forma uma unidade, uma práxis transformadora do sujeito.

\section{PROCEDIMENTOS METODOLÓGICOS}

Consideramos que promover o diálogo entre professores exige deste estudo métodos que sejam participantes, em que os sujeitos da pesquisa não sejam apenas números, mas tenham voz e possam ser escutados através da relação estabelecida entre si, entre eles e estas pesquisadoras. Para Le Bortef (1999, p. 52), a Pesquisa Participante (PP) garante este desejo, pois ela: 
[...] procura auxiliar a população envolvida a identificar por si mesma os seus problemas, a realizar a análise crítica destes e de buscar as soluções adequadas. Deste modo, a seleção dos problemas a serem estudados emerge da população envolvida, que os discute com os especialistas apropriados, não emergindo apenas da simples decisão dos pesquisadores. (LE BORTEF, p. 52)

Para o desenvolvimento deste estudo, lançamos mão do instrumento Diário de Bordo para fazer a coleta e o levantamento dos dados. O Diário de Bordo, foi acompanhado de uma ficha técnica com informações sobre identificação e formação. $O$ instrumento foi entregue às professoras do AEE que participaram das oficinas formativas. No início da primeira oficina, cada cursista respondeu sobre: "O que compreende acerca do ensino da Língua Portuguesa como L2?" e "O que diferencia o ensino da Língua Portuguesa para ouvintes e o ensino dessa mesma língua para os surdos?" Estas perguntas foram respondidas uma única vez. $\mathrm{O}$ intuito foi fazer um levantamento prévio sobre o entendimento que este profissional tinha sobre as metodologias de ensino desta língua antes de iniciar as formações. Posteriormente, ao término de cada oficina, o cursista respondia novamente ao Diário de Bordo colocando, dessa vez, o que ele modificaria em sua prática pedagógica com base nas discussões daquele encontro. Esse encaminhamento ocorreu em todas as quatro oficinas formativas.

Devido a esta carência de formação, fizemos a opção por escolher os professores das escolas de surdos de Salvador por sua experiência e saberes da prática. São profissionais que atuam nas escolas especializadas e conhecem esta realidade de perto, que, durante sua trajetória, tiveram erros e acertos.

As oficinas foram aplicadas pelos professores das escolas de surdos que já realizam uma prática exitosa de ensino do Português como L2. Foram transmitidas as experiências e compartilhadas as práticas já instituídas em sala para o ensino da segunda língua.

Em cada oficina, o professor aprendeu como trabalhar um determinado conteúdo de Português como L2 e, a partir daí, montar uma atividade para o seu aluno de acordo com a sua realidade e o que foi aprendido. Estas atividades foram realizadas em duplas pelos participantes das oficinas e, posteriormente, analisadas pelos docentes formadores visando darem retorno ou feedback àqueles professores. Estas atividades serviram para compor o material didático que desenvolvemos. 
Quanto à formação, esta ocorreu por etapas de forma semipresencial com uma carga horária de 80 horas. Dividimos a carga horária da formação da seguinte maneira: 4 (quatro) horas para estudos dos textos teóricos em casa, 8(oito) horas de oficinas formativas na escola e 8 (oito) horas para o desenvolvimento das atividades propostas nas oficinas que foram concluídas na escola, no momento da AC (Atividade Complementar) ou em casa, se assim desejassem.

$O$ caderno pedagógico de ensino de língua portuguesa com L2, cujo tema do material é: "EU, CONTANDO E FAZENDO HISTÓRIAS EM SÃO FRANCISCO DO CONDE", possibilita ao aluno a construção de um memorial sobre sua identidade, por meio das brincadeiras, das interações socioculturais e das vivências em diferentes situações em sua comunidade. $O$ intuito é que estas atividades possam colaborar no processo de letramento, na aprendizagem destes sujeitos e ser um subsídio aos professores.

\section{RESULTADOS E DISCUSSÕES}

Os resultados obtidos após a fase de coleta de dados, no diário de bordo, respondido pelos professores das escolas inclusivas que participaram das oficinas formativas, foram selecionados e agrupados segundo os critérios recomendados na análise de conteúdo. Na categoria - "Ressignificação das Práticas Pedagógicas" -, analisamos os escritos e dividimos em três subcategorias, de acordo com as falas que surgiam nos registros.

O profissional da Educação que hoje atua em sala de aula já passou por diversas experiências particulares sobre a sua profissão, já experenciou ser aluno e, durante essa trajetória, adquiriu conhecimento pessoal acerca da concepção do que é ser professor. Segundo Tardif (2002), os saberes que são adquiridos na trajetória pré-profissional têm um valor importante para a compreensão de sua natureza, do saber-fazer e saber-ser, que são estimulados e utilizados em sequência no próprio exercício do magistério.

Quando este professor vai para sala de aula, ele leva essa bagagem. É importante que estes saberes Ihes acompanhem, porém, muitas vezes, chegamos com reproduções de modelos de práticas que deram certo naquele período, naquele contexto, com aqueles sujeitos e que hoje precisariam ser repensadas. Ao se pensar 
num processo de formação, é importante levar em consideração essas questões e que se valorize a prática ao mesmo tempo em que esta seja refletida, que the possibilite compreender as situações novas, nos momentos de incertezas e imprecisões.

Alguns projetos de formação já utilizam o registro escrito como instrumento útil na discussão das práticas com os professores. Contudo, alguns desses instrumentos eram analisados a partir da visão do pesquisador, muitas vezes, era alguém que ia a campo pesquisar, mas que não estava envolvido no processo pedagógico.

A proposta do diário de bordo como instrumento de coleta de dados surge, então, como uma possibilidade de intervir na busca da transformação da prática dos professores, também como elemento importante na ressignificação da prática pedagógica, por possibilitar que os mesmos sejam capazes de descrever, identificar e até dialogar com as dificuldades, inquietações e vazios que se apresentam no decorrer da prática diária e que já não respondem satisfatoriamente aos objetivos propostos e desejáveis, portanto, passiveis de reestruturação e mudança.

Durante o período da formação, os professores que cursaram as oficinas (professores do AEE) receberam um diário de bordo. Ao término de cada oficina, eles teriam que refletir sobre o trabalho que já vêm desenvolvendo em sala e, a partir das discussões do encontro, o que elas mudariam em suas práticas pedagógicas para o ensino de Língua Portuguesa como L2.

Nesta categoria, surgem registros interessantes no diário por parte das professoras. Algumas relataram que já desenvolvem determinadas práticas recomendadas ou abordadas nas oficinas e que as orientações reforçaram conceitos e respaldaram suas práticas. Outros registros mostram que elas acrescentariam, mudariam e implementariam determinadas práticas devido ao conhecimento agora adquirido. Dividimos esta categoria de análise em três subcategorias, conforme registro abaixo:

\section{- $\quad$ Práticas já desenvolvidas}


sala de aula. A professora (...) trouxe alguns exemplos de recursos para serem trabalhados em sala de aula (vídeo, poemas, músicas, etc.).

Já costumo utilizar textos próximos da realidade dos alunos e, a partir de hoje, irei trabalhar ainda mais e explorar os materiais concretos e visuais.

Este encontro foi basilar para orientar meu trabalho quanto ao ensino da LP2. Já trabalhava com os gêneros textuais, mas ficava presa à parte do reconhecimento enquanto estrutura, falta explorar situações de uso da língua e trazer situações em que ele reconhecesse o uso dos gêneros no seu dia a dia.

Os relatos de algumas das cursistas evidenciam que elas já trabalhavam com certas orientações apresentadas para o ensino da Língua Portuguesa como L2. Como uma das propostas das oficinas se baseava na troca de experiências, era de se esperar que algumas das práticas apresentadas durante a formação já fossem utilizadas pelos cursistas no seu fazer pedagógico. É importante, nesses momentos de trocas, que os participantes percebam que os seus trabalhos não estão soltos, têm um direcionamento. Às vezes, o que falta são apenas alguns ajustes.

Ressalto também o tempo de atuar na educação de surdos dos professores cursistas, que é de 01 (um) a 03 (três) anos de experiência. Eles estão ainda caminhando em processo de buscas e descobertas. "Até porque é na experiência do trabalho docente que se desenvolvem as competências necessárias à profissão, e ocasião em que se desenvolve a identidade profissional" (ANDRADE, 2007, p. 60). É preciso tempo de carreira para construir as bases dos saberes profissionais.

- Mudanças de práticas

Eu trabalhava partindo do conteúdo para o texto, agora vejo que deve ser o inverso, pois o texto não pode ser usado como pretexto para o ensino da gramática.

A partir de agora, vou começar a trabalhar primeiro a ampliação de vocabulário, trabalhar as imagens como pistas visuais para posterior compreensão textual.

Fazer mais uso da contação de estórias e focar na ampliação da aquisição de Libras e aplicar a Pedagogia visual.

Através do encontro, gerou em mim uma reflexão sobre o meu fazer docente enquanto ao ensino de Língua Portuguesa como L2. Eu trarei mais contextualização visual e elementos paratextuais significativos. Eu fazia na minha prática docente, mas sem embasamento teórico ou de forma dissociada. Por exemplo: às vezes, trabalhava apenas os elementos gramaticais e desprezava os gêneros literários. Trazia o texto apenas para a interpretação e trabalhar elementos gramaticais. 
Os registros que compõem esta subcategoria podem indicar que as reflexões e orientações feitas durante o curso tiveram efeito positivo na disposição do professor cursista em considerar as especificidades de seu aluno surdo e reconsiderar suas práticas pedagógicas com base na compreensão dessas especificidades.

A escrita dos diários por parte das professoras demonstra, muitas vezes, a condição de inacabamento, Freire (1996, p. 50) diz que "Na verdade, o inacabamento do ser ou sua inconclusão é próprio da experiência vital. Onde há vida, há inacabamento. Mas só entre mulheres e homens o inacabamento se tornou consciente", fala-se aqui da necessidade de busca, de se reconhecer como alguém que está em movimento.

São nestes espaços de reflexão sobre a ação que podemos contextualizar os diários e estabelecer relação entre o que foi feito e o que poderá ser feito daqui por diante, ou seja, dar ressignificação à prática pedagógica. Por esse ângulo, percebese a importância de uma formação bem fundamentada com bases teóricas que embasem o fazer docente.

\section{- Novas práticas}

O encontro de hoje serviu para me mostrar o quanto é importante está agregando outros elementos tecnológicos ao ensino da língua portuguesa. Como os surdos são visuais, passarei a explorar os vídeos multimodais, este recurso, em minha prática.

Eu não fazia ideia de como trabalhar substantivos com surdos, mas a formação trouxe várias ideias de como trabalhar esse conteúdo como L2, adotando a metodologia de língua estrangeira.

Como novas aquisições a serem executadas em minha prática, incluirei o WhatsApp e o Facebook como textos possíveis de serem trabalhados.

Utilizar pistas textuais, formar glossários a partir dos textos trabalhados e deixar disponíveis para posteriores consultas.

Trabalhar com diversos textos, de acordo com o nível linguístico do aluno, e não pela série /ano.

Passarei a utilizar os textos do dia a dia, textos de circulação social.

As declarações presentes nesta categoria manifestam 0 desejo em desenvolver uma nova prática a partir do que apreenderam, das trocas feitas 
durante a formação. O diário constitui um instrumento importante para refletir e, depois, agir na sua práxis. Refletir sobre a ação apresenta a possibilidade de ressignificação das práticas pedagógicas. No entanto, falar sobre isso é muito subjetivo, depende do sujeito, não existe formação continuada ou instrumento que consiga aperfeiçoar um professor que não queira aprimora-se e não compreenda a valor desse processo de formação profissional.

Hoje, se aborda muito a reflexividade, que consiste no processo de tomar consciência da ação e pensar sobre o que se faz para que ocorra a modificação da prática. Mas não podemos deixar de levar em consideração que cada professor traz consigo, como pano de fundo, as representações que cada um tem, ou seja, suas experiências, situações. É preciso que se considere a realidade desse profissional e a suas condições de trabalho.

A transformação da prática dos professores deve se dar, pois, numa perspectiva crítica. Assim, deve ser adotada uma postura cautelosa na abordagem da prática reflexiva, evitando que a ênfase no professor não venha a operar, estranhamente, a separação de sua prática do contexto educacional no qual ocorre. (PIMENTA, 2002, p. 24).

Para essa autora, é indiscutível a contribuição da perspectiva da reflexão no exercício da docência, mas, apenas refletir sobre o trabalho docente em sala de aula é insatisfatório para um entendimento maior das condições que serão tomadas como facilitadoras ou não da prática em contextos escolares. A qualidade do exercício do professor também está condicionada pelos recursos humanos e materiais da escola.

Ao observar a prática docente sob o enfoque de uma perspectiva crítica, exigese ter o cuidado, como formadores, para que o destaque dado ao professor não venha a suprimir a importância do contexto escola - método de organização -, onde a prática ganha significado. É preciso considerar o ensino como uma prática social concreta.

Diante do cenário apresentado podemos e os resultados das análises evidenciaram que a formação continuada provocativa e reflexiva, aliada à busca de novos conhecimentos teórico-práticos, e a produção de materiais podem colaborar substancialmente para a ressignificação das práticas pedagógicas, vez que os participantes evidenciaram a necessidade e iniciaram o redimensionamento de suas práticas pedagógicas. 


\section{CONSIDERAÇÕES FINAIS}

Este estudo teve como intento auxiliar os professores em relação a alguns entraves existentes na educação dos surdos, como por exemplo, a formação de professores para o ensino da Língua Portuguesa como L2, buscando oportunizar, sobretudo àqueles que trabalham no $A E E$ com os surdos, uma formação especializada, já que pesquisas apontam para esta carência.

Como registrado pela literatura na área, são inúmeros os desafios na educação dos surdos, posto suas especificidades linguísticas e visuais. Compreendo que uma formação continuada não dará conta de atender a todas as necessidades da educação dos surdos. Os problemas existentes vão para além de uma formação, perpassam por questões históricas, sociais e culturais. Contudo, a pretensão, ao desenvolver este estudo foi de poder contribuir para a educação desses sujeitos na cidade de São Francisco do Conde/Bahia/BR, com um projeto de intervenção com vistas a amenizar a ausência de formação para o ensino da Língua Portuguesa na perspectiva de uma segunda língua.

Diante dessa realidade, percebemos que a proposta de formação continuada oferecida aos professores da rede municipal de SFC, no formato de oficinas formativas, aliada à produção de materiais didáticos, permitiu aos professores uma troca de experiências que contribuiu para um conhecimento mais efetivo da realidade do ensino de Língua Portuguesa como L2 e também repensar sobre suas práxis.

Embora esta pesquisa procure trazer para o "chão da escola" algumas questões referentes ao fazer pedagógico, reconhecemos que as temáticas aqui abordadas não se esgotam nesta modesta discussão oferecida à comunidade acadêmica, ao contrário, o que queremos é poder contribuir e provocar novas questões.

\section{REFERÊNCIAS}

ANDRADE, D. M. de M. Formação inicial e construção de saberes profissionais docentes: um estudo de caso no seio do Programa Rede UNEB 2000. 2007. 137 f. Dissertação (Mestrado em Educação) - Instituto de Educação, Universidade do 
Estado da Bahia, Cabula, 2007.

BRASIL. Presidência da República. Decreto 5.626, de 4 de abril de 2005. Regulamenta a Lei 10.436/02 que dispõe sobre a Língua Brasileira de Sinais Libras. Brasília: Casa Civil. Subchefia para Assuntos Jurídicos, [2005].

. Ministério da Educação e Cultura. Secretaria da Educação Especial. Política Nacional de Educação Especial, na perspectiva da Educação Inclusiva. Brasília: MEC/SEESP, [2008]. Disponível em: http://portal.mec.gov.br/arquivos/pdf/ politicaeducespecial.pdf. Acesso em: 5 dez. 2013.

Parecer CNE/CP n 9/2001. Diretrizes Curriculares Nacionais para a Formação de Professores da Educação Básica, em nível superior, curso de Licenciatura, de Graduação plena. Brasília: Diário Oficial da União, [2017].

Resolução CNE/CEB 2, de 1 de julho de 2015. Define as Diretrizes Curriculares Nacionais para a formação inicial em nível superior (cursos de licenciatura, cursos de formação pedagógica para graduados e cursos de segunda licenciatura) e para a formação continuada. Brasília: CNE, [2015].

BUENO, J. G. S. Crianças com necessidades educativas especiais, política educacional e a formação de professores: generalistas ou especialistas? Revista Brasileira de Educação Especial, Piracicaba, v. 3, n. 5, p. 7-26, set. 1999.

CAPOVILLA, F. Avaliação escolar e políticas públicas de Educação para os alunos não ouvintes. Revista Pátio, [S.I.], ano XIII, n. 50, p. 24-25, maio/jul. 2009.

CHARLOT, B. A pesquisa educacional entre conhecimentos, políticas e práticas: especificidades e desafios de uma área de saber. Revista Brasileira de Educação, v. 11, n. 31, p. 7-18, jan./abr. 2006.

FREIRE, P. Pedagogia da Autonomia. 23. ed. [S.I.]: Paz e Terra, 1996.

GOLDFELD, M. A criança surda: linguagem e cognição numa perspectiva sóciointeracionista. São Paulo: Plexus, 1997.

LE BOTERF, G. Pesquisa participante: propostas e reflexões metodológicas. In: BRANDÃO, C. (org.). Repensando a pesquisa participante. São Paulo: Brasiliense, 1999. p. 51-81.

PAGNEZ, K. S.; SOFIATO, C. G. O estado da arte de pesquisas sobre a educação de surdos no Brasil de 2007 a 2011. Educar em Revista, Curitiba, n. 52, p. 229-256, abr./jun. 2014.

PIMENTA, S. G. Professor reflexivo: construindo uma crítica. In: PIMENTA, S. G.; GHEDIN, E. (org.). Professor reflexivo no Brasil: gênese e crítica de um conceito. São Paulo: Cortez, 2002. p. 17-52.

RAMOS, D. M. Análise da produção acadêmica constante no Banco de Teses 
da Capes segundo o assunto educação de surdos (2005-2009). 2013. $81 \mathrm{f}$. Dissertação (Mestrado em Educação Escolar) - Faculdade de Ciências e Letras, Universidade Estadual Paulista, Araraquara, 2013.

SKLIAR, C. (org.). A surdez: um olhar sobre as diferenças. 4. ed. Porto Alegre: Mediação, 2010.

TARDIF, M. Saberes docentes e formação profissional. 2. ed. Petrópolis: Vozes, 2002.

\section{Sobre as autoras}

\section{Luciane Ferreira Bomfim}

Possui graduação em Pedagogia (2010). Professora de educação especial. Especialista em LIBRAS (2013) e Especialista em Atendimento Educacional Especializado (2014). Tem experiência na área de Educação, com ênfase em Educação Inclusiva e Especial. Mestrado pelo Programa de Gestão e Tecnologia aplicados à educação - GESTEC (2018). Atualmente é pesquisadora do TIPEMSE - Grupo de Pesquisa em Tecnologias, Inovação Pedagógica e Mobilização Social pela Educação da UNEB e o do TECINTED - Tecnologias Inteligentes e Educação.

\section{Cláudia Paranhos de Jesus Portela}

Graduada em Pedagogia (UEFS). Doutora em Educação (UNEB) com doutorado sanduíche pela Universidade de Lisboa. Mestre em Educação na área de Educação Especial (CELAEE/Cuba/UEFS). Especialista em Supervisão Escolar (UEFS) e em Educação a Distância (AVM). É professora adjunta do Departamento de Educação da Universidade do Estado da Bahia, atua como docente no Programa de Pós-Graduação em Gestão e Tecnologias aplicadas à Educação (GESTEC), coordena o Grupo de Pesquisa em Inclusiva e Diversidade/EDUCID, é professora pesquisadora do Grupo de Pesquisa em Formação Docente e Diversidade, coordena os Projetos de curso de Licenciatura em Educação Inclusiva e Educação Inclusiva na escola básica: superando limites, acolhendo desafios do Programa Institucional de Iniciação à Docência (PIBID). Compõe o Banco de Avaliadores do MEC/INEP/BASIS.

\section{Dídima Maria de Mello Andrade}

Professora permanente da Universidade do Estado da Bahia/PPGEDUC, programa de Mestrado e Doutorado. Professora adjunta B da Universidade do Estado da Bahia. Doutora em Educação Programa de Pós-Graduação em Educação e Contemporaneidade (UNEB). Mestre em Educação Programa de Pós-Graduação em Educação e Contemporaneidade (UNEB). Especialista em 
Psicopedagogia e em Supervisão Escolar Pedagoga. Atualmente é Coordenadora do Grupo de Pesquisa Tecnologias Inteligentes e Educação (TECINTED), membro do Grupo de Pesquisa Epistemologia, Estética, Linguagem e Subjetividade - EELIS e professora do Mestrado Profissional em Gestão e Tecnologias Aplicadas à Educação - GESTEC/UNEB. 